Trabalhonecessário

Issn: 1808 - 799X

ano 11, no $17-2013$

\title{
O TRABALHO DOCENTE NO CONTEXTO DE REFORMA EDUCACIONAL - AUTONOMIA E REGULAÇÃO EM QUESTÃO
}

\author{
Mariane Fernandes de Catanzaro \\ marianecatanzaro@yahoo.com.br ${ }^{1}$
}

\section{Resumo:}

Este artigo coloca em evidência o trabalho docente, no contexto de reformas constituídas nas políticas educacionais, no Brasil, a partir da década de 1990. As reflexões apresentadas são parte da dissertação de mestrado, "Entre choque e ordens: atravessamentos entre políticas educacionais e tensões na regulação do trabalho docente no sistema municipal de ensino do Rio de Janeiro", defendida no Programa de Pós-graduação em Educação, FFP-UERJ (2012). Inicialmente, fundamentados em referenciais teóricos, tais como Gramsci (2002) e Boom (2004), buscamos discutir questões mais gerais que envolvem o quadro de reorganização do capitalismo mundial (no pós 1970) e suas implicações nas mudanças tanto legislação nacional como um todo, quanto na regulamentação do exercício do magistério, seu reconhecimento e sua valorização. Em seguida, apresentamos uma reflexão acerca dessas implicações e suas interelações com a autonomia e a regulação da atividade docente. Finalmente, destacamos alguns resultados da análise documental de modo a apresentar e discutir algumas formulações que, para nós, além de afirmarem significativas alterações na legislação, ampliando a participação dos entes federados na organização dos sistemas de ensino, possibilitam novas formas de regulações extremas e delimitadoras do trabalho docente, com fortes repercussões no seu exercício.

Palavras-chave: Trabalho Docente. Reformas Educacionais. Regulação.

\footnotetext{
${ }^{1}$ Professora de Artes Visuais da SME-RJ, graduada em História da Arte (UERJ), com mestrado em Educação (FFP-UERJ).
} 


\title{
Trabalhonecessário
}

Issn: 1808 - 799X

ano 11, no $17-2013$

\begin{abstract}
:
This paper highlights the teaching work in the context of reforms made in educational policies in Brazil from the 1990s. The reflections presented here are part of the dissertation, "Between shock and orders: crossings between educational and tensions in the regulation of teaching in the municipal school system in Rio de Janeiro", defended at the Graduate Program in Education, FFPUERJ (2012). Initially, based on theoretical frameworks, such as Gramsci (2002) and Boom (2004), we discuss more general issues that involve the reorganization framework of world capitalism (post 1970) and their implications for changes in both legislation as a whole, as the regulation of the practice of teaching, their recognition and appreciation. Then, we present a reflection on those implications and their interrelations with the autonomy and the regulation of the teaching activity. Finally, we highlight some results of the document analysis in order to present and discuss some formulations which, for us, besides claiming significant changes in legislation, expanding the participation of federal agencies in the organization of education systems, enable new forms of regulations and extreme bounding of teaching, with strong repercussions in your exercise.
\end{abstract}

Key words: Teaching activities. Regulation. Education reforms. 


\section{Trabalhonecessário}

Issn: 1808 - 799X

ano 11, no $17-2013$

\section{Introdução:}

Limitar uma mudança educacional radical às margens corretivas interesseiras do capital significa abandonar de uma só vez, conscientemente ou não, o objetivo de uma transformação social qualitativa.

István Mészáros

Pretendemos, no presente artigo, refletir sobre o contexto da reforma educacional brasileira empreendida a partir da década de 1990, com vistas a compreender as mudanças definidas nas regulamentações que tratam da valorização e do reconhecimento do trabalho docente, considerando, especialmente, as questões que envolvem a autonomia e as formas de regulação desta atividade. ${ }^{2}$

Devemos registrar, desde já, que no nosso ponto de vista a compreensão da reforma educacional em geral, bem como das questões mais diretamente relacionadas ao trabalho docente, requer a consideração dos nexos entre as mudanças educacionais no contexto brasileiro e as mudanças políticas e econômicas vinculadas à reestruturação capitalista em escala mundial, constituídas a partir da década de 1970.

Como mostra Boom (2004), os ajustes realizados nas relações de trabalho no campo educacional, na América Latina, pós 1990, vinculam-se tanto aos ajustes da política educacional propostos por organismos internacionais, quanto a mudanças mais complexas na própria reestruturação das relações de trabalho, em geral, vinculadas às mudanças econômicas implicadas com a instauração do novo padrão de acumulação capitalista. Nessa perspectiva, as mudanças nas

\footnotetext{
${ }^{2}$ Cabe colocar que as questões aqui levantadas são parte da pesquisa de mestrado acadêmico, intitulada "Entre choque e ordens: atravessamentos entre políticas educacionais e tensões na regulação do trabalho docente no sistema municipal de ensino do Rio de Janeiro", defendida no Programa de Pós-graduação em Educação, da Faculdade de Formação de Professores, da Universidade do Estado do Rio de Janeiro, em São Gonçalo, no ano de 2012, sob a orientação da

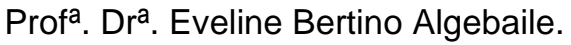




\title{
Trabalhonecessário
}

Issn: 1808 - 799X

ano 11, no $17-2013$

relações de trabalho, em geral, e as mudanças nas relações de trabalho no campo educativo escolar, em particular, vinculam-se a processos complexos de recomposição da hegemonia capitalista, envolvendo a própria tentativa de atualização da hegemonia dos países de economia central sobre os demais países, com vistas à manutenção das relações econômico-sociais que alimentam o mercado internacional (BOOM, 2004).

Vale lembrar que, no sentido atribuído por Gramsci, a hegemonia é referente a situações ou processos de supremacia política em que uma determinada fração de classe, para além de dominar as demais classes ou frações por meio do uso de recursos coercitivos, consegue dirigi-las em termos intelectuais e morais ${ }^{3}$. Essa "direção intelectual e moral", para Gramsci, não implica homogeneização, mas, ao contrário, certa capacidade do grupo dirigente em "harmonizar seus interesses e aspirações com os interesses e aspirações de outros grupos" (GRAMSCI, 2002; p.329). Nos termos de Gruppi (2000, p.70):

\begin{abstract}
A hegemonia é (...) capacidade de unificar através da ideologia e de conservar unido um bloco social que não é homogêneo, mas sim marcado por profundas contradições de classe. Uma classe é hegemônica, dirigente e dominante, até o momento em que através de sua ação política, ideológica e cultural - consegue impedir que o contraste existente entre tais forças exploda, provocando assim uma crise na ideologia dominante, que leve à recusa de tal ideologia, fato que irá coincidir com a crise política das forças no poder.
\end{abstract}

O conceito de hegemonia, portanto, é importante nesta discussão, na medida em que nos ajuda a perceber e a abordar o trabalho docente para além de suas características mais imediatas, considerando-o no contexto das complexas relações de poder que atuam na sua produção. É a partir dessas referências iniciais que procuramos entender a educação escolar no território brasileiro, hoje, considerando as relações que incidem sobre a organização da

\footnotetext{
${ }^{3}$ Gramsci (2000 e 2002) identifica dois principais processos de instauração de hegemonia: um referente à supremacia de uma fração de classe sobre as demais frações da mesma classe e outro referente à supremacia de uma classe sobre as demais.
}

TrabalhoNecessário - www.uff.br/trabalhonecessario; Ano 11, № 17/2013. 


\section{Trabalhonecessário}

Issn: 1808 - 799X

ano 11, no $17-2013$

ação estatal, relações estas que, como mostram autores como Frigotto (2008), envolvem não apenas as influências do neoliberalismo internacional, mas, principalmente, suas combinações com as forças conservadoras, de tradição patrimonialista, historicamente constituídas no Brasil.

De todo modo, os estudos sobre o trabalho docente, na nossa concepção, não limitam as atividades docentes à mera execução de tarefas escolares relacionadas à transmissão do conhecimento, uma vez que as especificidades desse trabalho estão para além das formas mais objetivas de produção laboral. Nesse sentido, essas especificidades não devem ser negligenciadas pelas reformas educativas implicadas com mudanças na regulamentação e nas formas de regulação da atividade docente.

O conjunto de atividades que compõem, hoje, aquilo que chamamos de trabalho docente, expressa decisões, escolhas e disputas vinculadas a mudanças no caráter atribuído à educação escolar e, portanto, a mudanças na organização da ação escolar como um todo. Ainda fundamentados em Gramsci (2000 e 2002), defendemos que esse conjunto de atividades também expressa, dentre outros aspectos, as condições de organização da categoria docente, o seu peso no âmbito das formulações políticas sobre a educação escolar, bem como os cenários socioculturais em que essa categoria emerge.

Nessa perspectiva, portanto, entendemos que a maneira como o trabalho docente é concebido e tratado nas políticas educacionais constitui um importante ponto de reflexão sobre o reconhecimento dessa profissão em um determinado contexto político-educacional.

Essas questões foram levadas em conta na organização deste artigo, no qual procuramos, no primeiro momento, discutir o quadro de mudanças ocorridas nas relações internacionais entre as décadas de 1970 e 1990, com vistas a 


\section{Trabalhonecessário}

Issn: 1808 - 799X

ano 11, no $17-2013$

destacar suas repercussões no Estado e, consequentemente, na organização das políticas públicas dos países economicamente periféricos ${ }^{4}$.

Em seguida detivemos nossa atenção à compreensão dos ajustes específicos no campo educacional e de suas implicações no trabalho docente, considerando, os recentes princípios e proposições para o trabalhador em geral que, em certa medida, passam a ser incorporados pelas mudanças nas formulações para a categoria docente.

As considerações sobre autonomia e regulação foram indispensáveis à análise e à compreensão desses ajustes nas regulamentações, especialmente por conta das mudanças que viriam ocorrer nas definições que tratam do reconhecimento e da valorização da carreira docente no contexto nacional, desde 1990.

Em caráter conclusivo, apresentamos alguns resultados obtidos das análises realizadas em determinados documentos federais, com vistas a evidenciar aqueles que lidam mais diretamente com aspectos e princípios que fazem referência à valorização e ao reconhecimento do trabalho docente.

\section{Mudanças econômico-sociais nas décadas de 1970 a 1990 e suas repercussões no Estado e nas políticas públicas educacionais}

Após a Segunda Guerra Mundial os países que compunham o bloco econômico capitalista ocidental passaram por um processo de reorganização das relações internacionais, em busca de uma nova expansão do capitalismo. Com base em estratégias político-econômicas, sustentadas pela assistência financeira e tecnológica internacional dos países industrializados, o crescimento econômico dos países do Terceiro Mundo seria estimulado, seguindo a mesma lógica

\footnotetext{
${ }^{4}$ Referimo-nos aqui, principalmente, aos países latino-americanos, dentre os países de economia periférica que há muito são objeto de ação e regulação, inclusive no âmbito educacional, por parte de países capitalistas centrais e de organizações internacionais e supranacionais por eles hegemonizadas.
}

TrabalhoNecessário - www.uff.br/trabalhonecessario; Ano 11, № 17/2013. 


\section{Trabalhonecessário}

Issn: 1808 - 799X

ano 11, no $17-2013$

desenvolvimentista pela qual os países desenvolvidos haviam passado (BOOM, 2004).

Nesse panorama, os países industrializados assumem posição de influência sobre os países subdesenvolvidos, garantindo subordinação e dependência de tecnologia e de desenvolvimento científico, de modo a proteger seus interesses, bem como suas vantagens em relação ao comércio mundial. Esse movimento de reestruturação do capitalismo tem como severo desdobramento o enraizamento dos princípios da mercantilização em todos os setores da sociedade e, de modo particularmente erosivo, no campo educacional.

Devemos destacar que os organismos internacionais ${ }^{5}$, por meio de ações sistemáticas apresentadas como "cooperação internacional", tiveram um papel fundamental nesse processo que estabelecia uma nova ordem mundial em nome da promoção dos avanços econômicos e sociais de que necessitavam os povos no pós-Guerra para resolverem seus "problemas de orden econômico, social, cultural e o de carácter humanitario" (BOOM, 2004; pg.73).

De acordo com Boom (2004), embora esses organismos não fossem portadores de um conjunto homogêneo de formulações e propostas, assim como de objetivos e mecanismos específicos de atuação, é certo que se constituíram e se fortaleceram, de maneira coletiva, como entidades fundamentais de produção, difusão e reprodução de conhecimento e de intervenção na organização do Estado e na configuração

...de los discursos, las técnicas, las metodologias y los esquemas teóricos y práticos destinados a abordar los problemas y a diseñar probables soluciones en diferentes campos, en particular el de la educación (BOOM, 2004; PG. 75).

As repercussões dessa perspectiva economicista no campo educacional afetaram tanto os sistemas de ensino, redefinindo parâmetros e prioridades para

\footnotetext{
${ }^{5}$ Tais como: o Fundo Monetário Internacional (FMI); o Banco Mundial (BM); o Banco Internacional de Desenvolvimento (BID); a Organização das Nações Unidas para a Educação, a Ciência e a Cultura (UNESCO); a Organização Internacional do Trabalho (OIT); o Programa das Nações Unidas para o Desenvolvimento (PNUD); a Comissão Econômica para a América Latina (CEPAL), entre outros.
}

TrabalhoNecessário - www.uff.br/trabalhonecessario; Ano 11, № 17/2013. 


\section{Trabalhonecessário}

Issn: 1808 - 799X

ano 11, no $17-2013$

as escolas públicas (TORRES, 1998), quanto os profissionais da educação, de modo geral, e o trabalhador docente, em particular, como revelam estudos sobre o tema, tais como os de Duarte (2011) e Bomfim (2012).

\section{As reformas educacionais vinculadas ao ajuste do Estado no Brasil}

Os anos 1990, no Brasil, foram decisivos para o campo educacional, especialmente por conta desse cenário de reformas políticas orientadas pelo discurso neoliberal, defensor do Estado mínimo e afirmativo de uma cultura de gestão fundamentada em concepções de flexibilidade e eficiência (DRAIBE, 1993).

As orientações neoliberais foram adotadas para a realização de uma reforma do Estado que envolveu medidas de privatização (por meio de venda, terceirização ou facilitação de expansão de mercado privado, incluindo práticas de verdadeira dilapidação do patrimônio público), de flexibilização de direitos trabalhistas e de racionalização da administração pública, dentre outras medidas que incidiram sobre a organização das políticas públicas sociais, incluindo a política educacional.

No campo educativo escolar, diversas medidas incidiram sobre a definição do trabalho docente em um sentido diverso do que vinha sendo afirmado nas lutas por democratização, ou seja, incorreram no sentido da regulação racional do trabalho docente, na contramão das medidas e ideias que se voltavam para 0 fortalecimento da autonomia (expansão das melhorias das condições de trabalho e da remuneração, do reconhecimento do trabalho docente como trabalho intelectual, etc.).

Nesse contexto, as proposições democráticas e participativas para a escola pública, almejadas pela sociedade e expressas por movimentos sociais de origens diversas, desde décadas anteriores, foram ajustadas às regulações do capitalismo mundial, provocando, como era de se esperar, "um profundo 
Issn: 1808 - 799X

ano 11, no $17-2013$

atrofiamento da esfera pública" nacional (FRIGOTTO, 2001; pg. 63). Embora o acesso à escola pública tenha sido alimentado pelo aumento do número de vagas em território nacional, essa escola configurou-se como um local de exercício desse atrofiamento e de consolidação de favorecimentos aos grupos que estipularam "as diretrizes da organização, as prioridades e conteúdos" a serem trabalhados (FRIGOTTO, 2001, p.64).

É importante alertar, ainda, que o caráter decisivo da educação para a economia é uma meta presente na base das estratégias privatizantes preconizadas pelas agências de fomento e corroboradas por segmentos da sociedade civil que desestimulam, abertamente, a participação política e favorecem a fragmentação e a despolitização do debate educacional, além de depreciar o público em relação ao privado na organização das instituições escolares (COUTINHO apud NEVES, 2002).

Essas contradições são consideradas, neste trabalho, com a finalidade de ajudar no esclarecimento do caráter e dos efeitos concretos de medidas de cunho conservador e regressivo que podem facilmente serem ocultadas por meio do emprego de termos vinculados às lutas pela democratização da educação escolar pública.

Um exemplo importante disso é dado por Oliveira (2007) ao mostrar que, embora as reformas educacionais, na América Latina, apontem, na última década, para uma "descentralização administrativa, financeira e pedagógica, atribuindo maior autonomia aos estabelecimentos escolares", identifica-se, ao mesmo tempo, uma padronização de normas e métodos que conduzem e definem suas gestões, no âmbito das secretarias de educação, através dos programas defendidos na condução da educação pública.

Os desdobramentos dessa perspectiva nas formulações que envolvem a escola, bem como nas determinações a elas destinadas provocam um movimento de mudanças efêmeras que, inconsistentes do ponto de vista das reais necessidades locais, são definidas com base em objetivos administrativos que, 


\section{Trabalhonecessário}

Issn: 1808 - 799X

ano 11, no $17-2013$

além de não alterarem as condições da escola e nem contribuírem para a sua transformação efetiva, tendem a tornar os cotidianos escolares estéreis e homogêneos (CATANZARO, 2012).

\section{A profissão e o trabalho docente no contexto das reformas da década de 1990}

O patamar de reconhecimento e valorização no qual se encontra a categoria docente, no contexto em questão, é um aspecto central a ser colocado em discussão, sobretudo por conta dos instrumentos de regulamentação e formas de regulação do exercício do trabalho do professor que vão se constituir nas diferentes esferas de governo.

Frigotto (2008; pg. 29), com base na perspectiva marxista, afirma que "é pelo trabalho que a espécie humana se produz". Para o autor, existem as mediações de primeira ordem e de segunda ordem na constituição do trabalho como criador da condição humana. As mediações de primeira ordem estão relacionadas às necessidades primeiras do ser humano e envolvem o equilíbrio, a organização, o controle das relações de trocas para que os requisitos matérias e culturais possam ser adequados e garantidos de modo não subordinativo ou hierarquizado. Em contrapartida, as mediações de segunda ordem são um atributo dos diferentes modos de produção da existência. No modo de produção capitalista, cada aspecto da relação homem-trabalho encontra-se subordinado e alterado de acordo com o imperativo da acumulação de capital.

Trata-se, portanto, de uma concepção que coloca o trabalho como atividade humana que se funda em relação direta com as regulamentações necessárias ao seu desenvolvimento, seja no plano de primeira ordem ou o de segunda ordem, mas que, em relação ao plano de segunda ordem, constitui-se de modo arbitrário e alienado. 


\section{Trabalhonecessário}

Issn: 1808 - 799X

ano 11, no $17-2013$

Essa dinâmica que se impõe ao homem e, ao mesmo tempo, transforma o trabalho criador em mercadoria e força de trabalho (lb., 2008) pode ser observada, por exemplo, por meio da análise das formas de constituição histórica das regulamentações. Essas análises traçam as determinações para a execução do trabalho e, de maneira sistemática, incidem sobre a regulação e a autonomia do trabalhador.

Em relação à autonomia do trabalhador, podemos afirmar que as noções de autonomia profissional presentes na discussão educacional são marcadas pela relação entre três dimensões relativamente distintas: a profissional; a escolar; e a da condição docente. Embora a dimensão da condição docente mereça destaque, alguns aspectos sobre as outras duas devem ser observados, uma vez que essas três dimensões se fazem complementares no entendimento da autonomia no campo educacional.

No plano profissional, identificamos três caminhos a serem privilegiados no reconhecimento dos sentidos da autonomia, aos quais duas dimensões podem estar associadas, a individual e a coletiva. As referências para compreender esses sentidos emergem em caminhos teóricos construídos tanto pela sociologia clássica do trabalho, quanto por meio da sociologia das profissões ou das ciências do trabalho, como indica Lessard (1999).

Lembremos que para a sociologia clássica do trabalho, de origem francesa e de inspiração marxista, a relação determinante é a relação salarial. $O$ trabalhador participa de um sistema trabalhista exploratório, submisso, alienado e dominado. O sentido de autonomia profissional é sustentado na luta pela liberdade e liberação das pressões e controles externos. A sociologia das profissões, de inspiração weberiana, afirma que a autonomia profissional remete ao "controle exercido pelo grupo sobre um campo de trabalho e suas diversas dimensões [...]". Liberdade de agir e de afirmar competências, valores e responsabilidades seriam condições aqui defendidas para além da liberação das pressões e dos controles. Já para as ciências do trabalho, a autonomia "está 


\section{Trabalhonecessário}

Issn: 1808 - 799X

ano 11, no $17-2013$

ligada ao exercício do julgamento em situação", o trabalhador "gerencia situações contingentes, indeterminadas e imprevisíveis". Nessa direção, o sentido de autonomia se relaciona "a uma obrigação prática associada à eficácia do trabalho" (LESSARD, 1999; CD-ROM).

Quando a questão da autonomia profissional aparece como um atributo prescrito pelo neoliberalismo, sua formulação no âmbito administrativo tem como pressuposto a exaltação do trabalho em equipe, estruturado por meio da divisão das etapas de produção, com vistas a responsabilizar cada etapa, bem como encarregá-las no gerenciamento das suas atividades (ib., 1999).

É importante frisar que essa forma de organização do trabalho não se coaduna, no nosso ponto de vista, com as especificidades do trabalho docente. No entanto compreender seu caráter, bem como o seu desenvolvimento na perspectiva neoliberal, nos ajuda a entender como funcionam determinados mecanismos de regulação que envolvem o trabalho do professor na atualidade.

Contudo, esse tipo de organização (partida, fracionada) do trabalho (no qual a fragmentação da produção se faz de modo impositivo, para atender a demandas político-econômicas da divisão internacional do trabalho, alimentadas pelas práticas neoliberais) tem a origem e o desenvolvimento da sua cadeia produtiva controlados, ainda que certos sentidos de "autonomia" possam ser identificados em documentos e discursos que fundamentam tal organização.

Como mostra Frigotto (2007), conceitos e categorias tais como flexibilização, autonomia, descentralização, participação são re-significados no plano das superestruturas e difundidos nos planos "econômico-social, ideológico, ético-político e educacional", já na forma metamorfoseada, de maneira a anunciarem alternativas para a "crise do capitalismo real". Essas alternativas são constituídas por "formas renovadas de exclusão, atomização do sistema educacional e dos processos de conhecimento e políticas autoritárias de descentralização" fundamentadas pelas teses da "sociedade do conhecimento e da qualidade total" (FRIGOTTO, 2007; p.78).

TrabalhoNecessário - www.uff.br/trabalhonecessario; Ano 11, № 17/2013. 


\section{Trabalhonecessário}

Issn: 1808 - 799X

ano 11, no $17-2013$

Acreditamos que, de mesmo modo, o próprio conceito de autonomia tornase, também, uma presa desse processo de apropriação e de ajustes de conceitos e categorias que, entremeado ao ideário neoliberal, se afirma no contexto da "reestruturação produtiva e globalização excludente", com vistas a produzir "novas formas de alienação do trabalho" (FRIGOTTO, 2008; p.25).

Cabe registrar que a autonomia pode ser definida, grosso modo, como uma situação, historicamente estabelecida, ou como uma condição, imediatamente definida, na qual indivíduos ou grupos de indivíduos encontram meios para exercerem atividades diversas, de maneira que suas percepções, seus sentimentos, suas emoções e seus conhecimentos adquiridos sejam respeitados e, sobretudo, valorizados como elementos indispensáveis à constituição dos modos de atuação e participação nos espaços em que praticam suas atividades.

Considerar as capacidades de observação, interpretação e compreensão da realidade, por parte dos atores envolvidos em determinada atividade, bem como reconhecer que cada um, coletivamente envolvido, é capaz de contribuir com diferentes potencialidades para o desenvolvimento ampliado das práticas em questão, pode ser um pressuposto para que a autonomia se faça presente e outras formas autônomas possam ser constituídas.

De todo modo, a autonomia possui uma forma que se constitui por uma complexa rede de relações e variáveis emergidas em função do contexto onde está situada. Essas relações e variáveis estão conectadas ao tipo da atividade exercida, bem como às especificidades decorrentes dos processos históricos, econômicos, políticos e ideológicos que envolvem cada profissão. No caso da autonomia no trabalho docente o conjunto dessas especificidades não se dá apenas em função de objetividades, mas também de subjetividades implicadas no contexto escolar como um todo. 


\section{Trabalhonecessário}

Issn: 1808 - 799X

ano 11, no $17-2013$

\section{Autonomia docente no cenário de constituição da autonomia escolar}

Se considerarmos, em primeira instância, o trabalho docente na perspectiva do seu exercício cotidiano, deixando de fora dessa análise imediata não apenas a formação desse profissional (tanto a inicial quanto a continuada), mas, também, as reais condições de exercício da sua atividade na escola (administrativa e pedagogicamente externa e/ou internamente organizadas), bem como a remuneração desse trabalhador, podemos destacar alguns aspectos da sua prática que são fundamentais ao debate sobre autonomia no âmbito da docência e, de modo relacional, da escola. Entendemos que algumas particularidades ficam à margem dos processos oficiais de institucionalização das funções, bem como das definições que orientam as obrigações do trabalho do professor.

Vale lembrar que o trabalho do professor envolve atribuições que extrapolam do campo das funcionalidades previstas para ações e atividades que não se enquadram nos tipos de atribuições oficialmente reconhecidas, mas que são fundantes de um tipo de relação específica. Estamos querendo dizer que o trabalho do professor, além de lidar com questões objetivas de organização de métodos, conteúdos, conceitos e abordagens específicas do campo com o qual lida, constitui-se, também, por um conjunto de responsabilidades que não participa do rol das responsabilidades oficialmente prescritas, mas que, nem por isso, são menos importantes.

Entendemos, ainda, que as especificidades do trabalho docente não oficialmente explicitadas resultam de um tipo de relação dinâmica entre os sujeitos que integram o processo educativo escolar, ou seja, entre alunos, demais professores, profissionais, famílias e atores da comunidade escolar de modo geral. Essa característica do trabalho docente, fundamental, mas não exclusiva e, mesmo, dependendo do contexto, não reconhecida como central, é que nos provoca a reflexão acerca dos sentidos de autonomia implicados com esse tipo de 


\section{Trabalhonecessário}

Issn: 1808 - 799X

ano 11, no $17-2013$

trabalho. Além disso, como o centro dessa forma de trabalho não está na relação com os conhecimentos apenas, mas também na relação entre os sujeitos atuantes, trata-se de sentidos de autonomia obrigatoriamente referidos às construções e acúmulos coletivos que dão base ao processo educativo escolar.

Devemos frisar que a autonomia escolar, hoje, integra um conjunto de reformas e mudanças globais ocorridas na administração educativa com o objetivo de se instituir a descentralização ${ }^{6}$ político-administrativa dos estabelecimentos de ensino. Barroso (2010) aponta a existência de dois planos distintos que devem ser considerados nesse processo de constituição da autonomia escolar: o que se refere às relações político-administrativas das escolas; e o que diz respeito às relações e dinâmicas sociais de cada organização escolar, as quais "para lá das determinantes político-administrativas, produzem formas de regulação autônoma". O autor destaca que a "autonomia construída" é resultante de um movimento de interação, social e política, de "diferentes atores num determinado contexto organizativo" e, nesse sentido, "não existe, verdadeiramente, uma autonomia decretada, contrariamente ao que está subjacente às mais diversas estratégias reformistas, nesse domínio" (ib., pg. 44).

O papel do Estado, nesse processo de reordenação política, através do qual novos modos de regulação tanto das políticas, quanto das ações públicas se fazem perceber no campo educacional, tem fundamental relevância, sobretudo quando se identifica "a passagem de uma regulação burocrática para uma regulação pós-burocrática e de uma governação pelas normas para uma governação pelos instrumentos" (ib., pg. 64), como no caso das reformas ocorridas no Brasil, a partir da década de 1990.

Entendemos que o Estado liberal não se firma à sociedade contemporânea por meio da força e da opressão, mas se estabelece de modo a organizar as

\footnotetext{
${ }^{6}$ A descentralização é um mecanismo de governo utilizado, não raramente, numa perspectiva de desconcentração. Para Lobo (1990; p.74), a descentralização "significa uma alteração profunda na distribuição de poder", ao passo que a desconcentração está relacionada a "mudanças que levam em conta uma dispersão físico-territorial das agências governamentais que até então estavam localizadas centralmente".
} 
Issn: 1808 - 799X

ano $11, \mathrm{n}=17-2013$

relações sociais com base em atravessamentos que conectam, constroem uma forma de vida social "que se apresenta como desconectada, como mecanicamente dispersa e fragmentada". Não se trata de um processo simples e linear, mas de uma conjugação de interesses que se estabelece por meio de "intensas disputas, lutas sociais e correlações de força que, certamente, envolvem maquiavelismos e manipulações", bem como por meio de "manifestações e reivindicações mais ou menos organizadas" de setores não dominantes, ou seja, pelas lutas de classes (FONTES, 2008; p.15).

Os instrumentos de governação que resultam desse jogo de atravessamentos visam, em primeiro plano, cuidar da produção de trabalhadores, livres, para que esses trabalhadores possam "apresentar-se ao mercado e assegurar a produção de todos os demais bens" (ib.; p.16).

Esse novo modelo de práticas institucionais capitalistas é carregado de critérios de concorrência, produtividade, avaliação, competências, autonomia das instituições, tensões entre desregulamentação das relações de trabalho e maior pressão por resultados. Dessa forma, novos dispositivos de ensinoaprendizagem, bem como uma nova lógica de regulação são introduzidos em função da necessidade de maximizar o rendimento escolar. Nessa perspectiva, os resultados são considerados mais importantes do que os processos ou os desdobramentos do trabalho docente sobre outras "capacidades" de seus alunos (como, por exemplo, capacidade de mobilizar seu interesse e/ou curiosidade, formulações críticas sobre a realidade, criatividade e outras atitudes autônomas).

\section{Contradições entre trabalho docente e força de trabalho: a subordinação docente à lógica da produtividade}

O trabalho docente, hoje, vem sendo tratado, no nosso ponto de vista, como similar a qualquer trabalho produtor de mercadorias. Assim, as medidas que visam regulamentar e definir aspectos do trabalho docente são, comumente, 


\section{Trabalhonecessário}

Issn: 1808 - 799X

ano 11, no $17-2013$

marcadas por tentativas de ajustar o trabalho do professor a parâmetros organizacionais típicos dos processos e das relações de trabalho empresariais.

No entanto, entendemos que o trabalho docente tem um caráter distinto do trabalho subordinado ao processo produtivo, uma vez que a atividade do professor é necessariamente uma prática criativa que, para se realizar, precisa de liberdade, de autoria individual e coletiva (tanto pedagógica, quanto administrativa e intelectual).

Vale destacar que a crise econômico-financeira que emergiu nas sociedades capitalistas na segunda metade do século XX impôs a necessidade de reestruturação das políticas de Estado, bem como de reorganização das bases produtivas ao conjunto de países (centrais e periféricos) que objetivavam garantir a funcionalidade do capitalismo. Nesse contexto, já não era suficiente, para transformar as bases produtivas, apenas o desenvolvimento científico e tecnológico, uma vez que a classe trabalhadora deveria, para êxito dessa nova investida de manutenção da relação capital-trabalho, estar conivente, por convencimento, com atuações e intervenções do Estado.

Para Miranda, o novo modelo (mais flexível na forma de gerir a produção) da relação entre o trabalho e o capital viria a gerar novos mecanismos de "subsunção, controle e cooptação da classe trabalhadora" (pg. 2; 2006), em todas as modalidades trabalhistas, inclusive no trabalho docente.

Os ajustes políticos foram conduzidos no campo educacional através da combinação de interesses diversos, com significativas implicações para os sistemas de ensino, nas diferentes esferas: municipal, estadual e federal.

As reformas educacionais, encaminhadas nos anos 90, provocaram mudanças na organização do trabalho escolar e, consequentemente, no trabalho docente. Conduzidas sob os critérios de excelência e produtividade, as políticas educacionais, no contexto latino-americano, visavam à expansão da 


\section{Trabalhonecessário}

Issn: 1808 - 799X

ano 11, no $17-2013$

escolarização básica a todo custo, inclusive ao custo da massificação do ensino (OLIVEIRA, 2002) ${ }^{7}$.

Dois aspectos interligados podem ser evidenciados no decorrer desse processo de expansão da escola pública: um diz respeito ao processo de intensificação da tendência, já constituída historicamente, de tomar o trabalho do professor como força de trabalho "comum", com base nos princípios de concorrência, disponibilidade, mercantilização da atividade do trabalhador etc.; o outro, implicado no primeiro, se destaca em função da pulverização (fomentada pelo novo modelo de organização da escola) das especificidades do trabalho docente. Cabe ressaltar que esse modelo atende a objetivos externos que tornam secundárias as necessidades escolares locais.

Entretanto, considerar a força do trabalhador docente exclusivamente do ponto de vista da sua relação com a organização do trabalho escolar (o modo como é organizado o trabalho do professor e dos outros trabalhadores da instituição: formas de discriminação das atividades; divisão do tempo; distribuição de tarefas e competências etc.) significa ignorar que sua constituição histórica, além de ser amarrada a mecanismos objetivos complexos, é perpassada por subjetividades específicas do tipo de relação de trabalho que precisa se estabelecer para dar curso ao processo educativo escolar. Subjetividades essas que, por vezes, tornam-se presas de favorecimentos e subordinações, tanto material (formas de organização do trabalho docente, participação do professor na estruturação dos processos formativos etc.), quanto intelectual (concepções político-pedagógicas, modelos de ensino-aprendizagem, perspectivas ideológicas e, ainda, a própria construção da subjetividade dos professores).

As reformas educacionais empreendidas na década de 1990 reduziram a questão da Educação no Brasil ao problema da "eficiência da gestão do setor

\footnotetext{
7 Vale lembrar que a LDB 9394/96 é resultado dessa composição, estabelecida sob a ordem da redemocratização do país ("ampliação" da participação de segmentos da sociedade nos debates políticos), mas sancionada na forma de um texto achatado pelas perspectivas que o mercado impunha aos modelos educacionais dos países periféricos.
} 


\section{Trabalhonecessário}

Issn: 1808 - 799X

ano 11, no $17-2013$

educacional e do ensino, enfatizando questões administrativas e pedagógicas", deixando de fora da discussão as "relações que efetivamente produziram uma escola que não ensina e dos limites de uma escola assim configurada frente ao agravamento do quadro social". O problema da escola pública, nessa perspectiva, ficava limitado, assim, apenas à questão da sua dependência frente à "modernização da administração pública, da escola e do professor" (ALGEBAILE, 2009; pg. 79).

Embora o "fisiologismo, o clientelismo e o despreparo profissional" tenham sido "apontados como causas da ineficiência escolar", as propostas de governo não avançaram no sentido da sua compreensão e nem, tão pouco, da sua transformação, uma vez que os mecanismos que os promoviam não foram postos em discussão (ib.; p. 79).

A dinâmica que se instituiu nesse processo de desqualificação e redução do debate sobre as complexas relações que envolviam a Educação, no panorama político do momento, deixa transparecer disputas e consentimentos estabelecidos em decorrência da dominação política e econômica que se apresentava e, ao mesmo tempo, que se fizeram necessários à manutenção da concentração do poder nas mãos de frações específicas da sociedade.

A descentralização administrativa, financeira e pedagógica, alimentada pelas políticas emergentes, promoveu maior autonomia formal às escolas públicas, ao mesmo tempo em que aumentou suas responsabilidades. As escolas passam a ter de responder a um conjunto de obrigações cujas formulações não Ihes cabe, uma vez que a busca por uma maior eficácia do ensino tem seus princípios estruturados fora do contexto escolar. Para Oliveira (2007), "o paradoxo desse modelo regulatório é que, ao mesmo tempo em que cresce a autonomia dos sujeitos, também cresce o controle sobre eles" (pg. 367).

Nesse cenário, o conhecimento, ferramenta (imaterial) de trabalho do professor, é reestruturado de acordo com novas regras de organização da força de trabalho, em geral, e da "força de trabalho" específica que atua na sua 


\section{Trabalhonecessário}

Issn: 1808 - 799X

ano 11, no $17-2013$

transmissão escolar, sob processos regulatórios que atendem a níveis diferenciados de poder e se constituem em meio a atravessamentos políticos observados na relação entre a autonomia e a regulação no âmbito das definições que incidem sobre o exercício da profissão docente.

\section{Regulação e políticas de Estado na Educação: instrumentos de governamentalidade}

As políticas formuladas no contexto de buscas por conciliação entre interesses de frações de classe dominante nacionais e estrangeiras, a partir da década de 1990 no Brasil, foram consagradas por um tipo de intervenção estatal que se fundamentava na exaltação da regulação da administração pública ${ }^{8}$.

Na perspectiva em que estamos discutindo, a regulação pode ser um modo através do qual o Estado opera diferentes dispositivos que visam assegurar formas particulares de direcionamento da ação para um coletivo através do que podemos denominar de "movimentos de política", isto é, processos de formulação e de implementação de políticas que envolvem articulação de interesses e objetivos de determinadas frações da sociedade.

De acordo com Foucault, as ações das instituições, dos aparelhos e de diferentes mecanismos de Estado não devem ser entendidas como cunhadas no seu interior, pois "o Estado não é em si uma fonte autônoma de poder" (FOUCAULT, 2008). Ao contrário, o Estado é um conjunto de:

\footnotetext{
Transações incessantes que modificam, que deslocam, que subvertem, que fazem deslizar insidiosamente [...] as fontes de financiamento, as modalidades de investimento, os centros de decisão, as formas e os tipos de controle, as relações entre autoridades locais, a autoridade central etc. [...] o Estado não tem entranhas [...] não tem interior. $O$
}

\footnotetext{
${ }^{8}$ Para Barroso (2006), a regulação é um tipo de intervenção estatal "mais flexível na definição dos processos e rígida na avaliação da eficiência e da eficácia dos resultados", diferente, portanto, do tipo de intervenção estabelecida na forma da regulamentação, uma vez que esta estaria "centrada na definição e controlo a priori dos procedimentos e relativamente indiferente às questões da qualidade e eficácia dos resultados" (pg. 63).
} 
Issn: 1808 - 799X

ano 11, no $17-2013$

Estado não é nada mais que o efeito móvel de um regime de governamentalidades múltiplas $^{9}$ (ib., p. 106).

A compreensão sobre o contexto político, portanto, é fundamental para a análise dos mecanismos de regulação implicados nesse contexto, sobretudo por que esses mecanismos, conforme defende Barroso (2006), podem ser apreendidos por meio de duas abordagens distintas, porém complementares, ou seja: via a apreensão do Estado pela sua ação; e, também, pela apreensão dos instrumentos utilizados pelo Estado na condução das suas ações.

Os instrumentos utilizados pelo Estado (programas, projetos, ações políticas e sociais etc.) constituem outro conjunto de elementos significativos do ponto de vista da concepção de regulação a qual o Estado é defensor. Além disso, esses instrumentos de ação pública abrangem diferentes modalidades de regulação (econômica, social, política, administrativa) que são estabelecidas sob graus diversos de coerção, indução e convencimento, dependendo de fatores como para quem se destinam e qual o alcance da sua operacionalização.

Alguns tipos de regulação podem ser observados no campo educacional por meio de ações de governo que são planejadas para orientar o funcionamento dos sistemas de ensino. Para Barroso (2006), o conceito de regulação pode ser utilizado para descrever tipos - diferentes, mas interdependentes - de fenômenos que ocorrem no contexto dos processos de produção e aplicação das regulações. De acordo com o autor, as análises dos modos como se constituem as regras e

\footnotetext{
${ }^{9}$ Foucault (2008) nos mostra como a razão governamental se constitui no Estado moderno a partir da interação de elementos que compõem a nova governamentalidade (economia, população, segurança e liberdade), com o objetivo de esclarecer que as intervenções estatais vão estar limitadas em função da necessidade de se garantir a segurança dos fenômenos naturais (ou seja, "os processos econômicos ou os processos intrínsecos à população") através dos "mecanismos de segurança", mecanismos esses operados de forma a se respeitar, necessariamente, a liberdade. O Estado aparece não mais como interventor autoritário que "vai regulamentar, sob a forma da polícia, o espaço, o território e a população", esse Estado intervém de maneira à deixar agir os mecanismos do interesse particular, que estarão, assim, por fenômenos de acumulação e de regulação, servindo a todos" (pg. 466). É a razão econômica a "nova razão de Estado", razão essa que assume novas formas e instrumentos de governamentalidade, a governamentalidade dos economistas, sobre a qual vão se firmar "linhas fundamentais da governamentalidade moderna e contemporânea" (ib., p.468).
} 


\section{Trabalhonecessário}

Issn: 1808 - 799X

ano 11, no $17-2013$

como essas são aplicadas, bem como dos modos como os atores envolvidos nesses processos se apropriam delas e as transformam são fundamentais para a compreensão tanto do tipo de intervenção ao qual essas regras estão submetidas, quanto do processo de (re)ajustamento dessas mesmas regras por parte dos atores implicados.

No caso da introdução de regras no âmbito educacional, Barroso (2006) identifica dois tipos de regulação que, no nosso ponto de vista, assumem posições relevantes para 0 debate em questão. Um, denominado de "microregulação local", se constitui como um conjunto de "estratégias, negociações e acções, de vários actores, pelo qual as normas, injunções e constrangimentos da regulação nacional são (re)ajustadas localmente, muitas vezes de modo intencional" (ib.; pg. 56). O outro, definido como "regulação interna", é aquele onde estão localizados "os processos formais e informais que garantem a coordenação da acção coletiva na escola, através da produção e da manutenção de regras que asseguram o seu funcionamento", por meio de três tipos mais específicos de regulação: "regulação de controle", "regulação autônoma" e "regulação conjunta" (REYNAUD APUD BARROSO, 2006; pg. 171).

Nessa perspectiva, assinalamos dois aspectos: 1) as regulações são produzidas por processos que visam difundir perspectivas, programas e projetos de políticas específicos e, nesse sentido, esses processos podem ser observados com base na análise dos sentidos e significados previamente constituídos (programas de governo, por exemplo); 2) para que esses sentidos e significados possam ser difundidos faz-se necessário o estabelecimento das regulações que organizam e orientam tais difusões, por meio de práticas, mecanismos e tecnologias de controle e ordenamento.

A análise de documentos que regulamentam a educação, bem como o exercício do trabalho docente, em especial, pode ser reveladora de princípios que, ocultos ou não, tendem a dar suporte à elaboração e ao exercício de tipos 


\section{Trabalhonecessário}

Issn: 1808 - 799X

ano 11, no $17-2013$

distintos, porém decisivos, de regulação no âmbito das organizações dos sistemas de ensino.

\section{Alguns documentos em questão: parâmetros do exercício do trabalho docente}

No quadro de redimensionamento das políticas sociais (década de 1990, no Brasil), em que as políticas educacionais não emergem descoladas das prescrições econômicas, os sistemas de ensino são levados a se adequarem às novas demandas formativas e, no fluxo desses ajustes, o trabalhador docente é enquadrado pela necessidade que tais demandas têm de sistematizar e difundir o princípio de eficiência preconizado pelo neoliberalismo internacional.

A análise de peças da legislação educacional a partir de fins da década de 1980, correlacionada às Resoluções expedidas pelo Conselho Nacional de Educação - Câmara de Educação Básica (CNE-CEB), no mesmo período, com destaque, particularmente, para os parâmetros que envolvem o exercício do trabalho docente, possibilitou a identificação de possíveis avanços e/ou retrocessos presentes nas suas formulações.

Contudo, os parâmetros de exercício do trabalho docente constituem os mecanismos que definem e/ou normatizam as condições de atuação do profissional do magistério, de maneira a envolver um conjunto de aspectos diversos, cujas origens vão desde a remuneração até a participação docente na elaboração e no planejamento das ações de caráter educativo, estabelecidas tanto nas redes de ensino como um todo, quanto nas escolas.

Entendemos que aspectos referentes à jornada de trabalho, à remuneração, à progressão na carreira, aos incentivos e apoios, técnico e financeiro, bem como à participação na elaboração, planejamento, execução e avaliação do projeto político-pedagógico da escola e da rede de ensino constituem elementos fundamentais à compreensão do quadro atual que 


\section{Trabalhonecessário}

Issn: 1808 - 799X

ano 11, no $17-2013$

regulamenta o exercício do trabalho docente e que tem implicações diretas na sua prática.

De acordo com a Resolução CNE/CEB no 3, de 1997, devem ser assegurados período de 45 dias de férias anuais e jornada semanal de, no máximo, 40 horas, a ser composta por horas aula e horas de atividades, sendo que estas devem circunscrever-se a um mínimo de 20 e um máximo $25 \%$ de horas de atividades. É fundamental destacar que, nos termos da Resolução $n$ ํ 3, em conformidade com a LDB de 1996, as horas de atividades incluem preparação e avaliação do trabalho didático, colaboração com a administração da escola, reuniões pedagógicas, articulação com a comunidade e aperfeiçoamento profissional, de acordo com a proposta pedagógica de cada escola (art. $6^{\circ}$, inciso IV).

A Lei do Piso (11.738 / 2008) também reconhece que o trabalho docente não se encerra na sala de aula e, portanto, sanciona a obrigatoriedade de composição da jornada de trabalho observando-se "o limite máximo de 2/3 (dois terços) da carga horária para o desempenho das atividades de interação com os educandos" (art. $2^{\circ}, \S 4^{\circ}$ ).

A Resolução CNE/CEB no 2 de 2009, embora não trate da composição das horas de trabalho, destaca critérios que, no nosso ponto de vista, são estratégicos na aplicação das políticas educacionais. Visto que a contemplação total ou parcial desses critérios, por parte das políticas implementadas por esferas municipais, por exemplo, pode nos fornecer elementos de ponderação sobre o grau de comprometimento dos sistemas educacionais com a valorização e o reconhecimento do trabalho do professor.

Essa mesma Resolução destaca a necessidade de os entes federados promoverem a participação docente na elaboração, no planejamento, na execução e na avaliação do projeto político-pedagógico da escola e da rede de ensino.

TrabalhoNecessário - www.uff.br/trabalhonecessario; Ano 11, № 17/2013. 
Issn: 1808 - 799X

ano 11, no $17-2013$

Vale observar que, em relação à LDB 9.394/96, essa Resolução representa um avanço na definição sobre a participação docente, uma vez que os artigos $13^{\circ}$ e 14ํำ desta Lei determinam que o professor deve participar da elaboração de propostas e projetos pedagógicos dos estabelecimentos de ensino, ou seja, esses artigos não fazem menção à necessidade de participação dos professores na elaboração dos projetos que se aplicam, de modo generalizado, nas redes de ensino.

No entanto, o não reconhecimento da necessidade de participação dos professores, nesses processos de organização dos sistemas de ensino, pode gerar ações arbitrárias diante das próprias necessidades locais, o que, num município de grande porte (como o Rio de Janeiro, por exemplo) tende a contribuir com um não reconhecimento de carências específicas das diferentes comunidades que o integram, bem como das condições de trabalho docente que, por si, são fundamentais à melhoria da qualidade de ensino.

\section{Considerações finais: aspectos relevantes quanto à autonomia e à regulação do trabalho docente}

Compreendemos que os aspectos relacionados à autonomia ou à regulação do trabalho docente podem ser identificados em dois tipos de disposições: as que, nitidamente, dizem respeito à participação dos professores nos processos decisórios relativos à ação escolar e mesmo ao trabalho do professor; e aquelas que se referem ao estabelecimento das condições de trabalho que, por si, são indicativas do reconhecimento da necessidade de condições básicas para que o professor possa se dedicar à organização do que constitui o centro da sua atuação.

Duarte (2011) defende que, na América Latina, "o processo de reorganização escolar" vem "atropelando" as atividades, "reconhecidas como 


\section{Trabalhonecessário}

Issn: 1808 - 799X

ano 11, no $17-2013$

'clássicas' do trabalho docente", em função das novas exigências impostas ao "exercício da profissão" (pg. 166).

Frente a isso, podemos dizer que as mudanças observadas tanto na legislação brasileira, quanto na organização dos sistemas de ensino e, consequentemente, nas orientações para o trabalho docente, nos últimos 20 anos, podem indicar, simultaneamente, um avanço e um retrocesso nas concepções sobre a valorização e o reconhecimento do trabalho do professor. Enquanto os sistemas públicos de ensino "ganharam" mais autonomia para deliberarem sobre questões políticas, financeiras e pedagógicas, as avaliações externas amarraram seus projetos àqueles que se definiram fora dos contextos escolares, de maneira a intensificar e a engessar o trabalho dos professores.

A presença do nível central de governo na abordagem da questão não tem se limitado à regulamentação, sendo notória sua crescente atuação na definição de programas de ação que, orientados para a organização, a ação e o desempenho escolar, atingem em cheio a função docente, pelas mais diferentes vias.

Enquanto o Brasil avança a duras penas nesse terreno da regulamentação, com honoráveis entraves e contenções, como no triste e exemplar caso do processo jurídico movido por estados e municípios contra a aplicação dos novos parâmetros de composição da carga horária docente ${ }^{10}$, o terreno das regulações expande-se a olhos vistos, consolidando tendências que, por sua disseminação,

\footnotetext{
${ }^{10}$ Trata-se do processo movido por estados e municípios contra o disposto no parágrafo $4^{\circ}$ do artigo $2^{\circ}$ da Lei ํㅜ 11.738/2008, relativo à estipulação do limite máximo de $2 / 3$ (dois terços) da carga horária docente para o desempenho das atividades de interação com os educandos, o que, por exclusão, representaria a reserva de $1 / 3$ da carga total de trabalho para atividades de preparo de aula, formação, planejamento, dentre outras vinculadas ao auto-preparo e preparo coletivo do professor. O fato de que estados e municípios tenham entrado na justiça não implicou apenas a suspensão da entrada em vigência dessa disposição por 4 anos, mas condicionou toda a regulamentação do CNE acerca da elaboração dos planos de carreira dos profissionais da educação impedindo a fixação de parâmetros mais claros relativos ao conteúdo concreto das diferentes frações de tempo do trabalho docente.
} 


\section{Trabalhonecessário}

Issn: 1808 - 799X

ano 11, no $17-2013$

passam a ter 0 peso de normas, tanto mais problemáticas quanto mais concorrentes com o teor das atenuadas conquistas nas regulamentações.

Chamamos atenção para determinados tipos de relação em que novas regulamentações demandam regulações extremas e insidiosas em grupos específicos, categorias de profissionais ou, até mesmo, na classe trabalhadora como um todo, como, grosso modo, identificamos no avanço das políticas neoliberais.

Por fim, cabe observar que as intervenções no trabalho docente se realizam por meio de mecanismos que são portadores, nem sempre visíveis, de rotinas, pautas, agendas, parcelarizações do processo de trabalho, transformismos do seu conteúdo e formas de gestão de relações que, em conjunto, impõem uma nova cultura institucional, novos modos de ser, pensar e agir no contexto educativo escolar. 


\section{Trabalhonecessário}

Issn: 1808 - 799X

ano 11, no $17-2013$

\section{BIBLIOGRAFIA:}

ALGEBAILE, E. A desigualdade recriada: as políticas de educação e cultura na construção dos sentidos sociais da arte. Dissertação de Mestrado em Educação. Universidade Federal Fluminense. Niterói/RJ, 1996.

BARROSO, João. A regulação das políticas públicas de educação: espaços, dinâmicas e actores / org. João Barroso (Ciências da Educação:1). Educa/Unidade de I\&D de Ciências da Educação. Universidade de Lisboa / Alameda da Universidade / Autores, 2006.

BOMFIM, Maria Inês. O tempo, a técnica e a produtividade: o Banco Mundial e o trabalho docente no Brasil. IX Seminário de La Red Estrado / Políticas Educativas para a América Latina: praxis docente y transformación social. Universidad de Chile, Santiago do Chile, Julio de 2012.

BOOM, Alberto Martínez. De La escuela expansiva a La escuela competitiva: Dos modos de modernización educativa em América Latina. Anthropos Editorial. Bogotá, 2004.

BRASIL. Lei 9.394, de 20 de dezembro de 1996. Estabelece as diretrizes e bases da educação nacional.

. Lei 11.738 , de 16 de julho de 2008. Regulamenta a alínea "e" do inciso III do caput do art. 60 do Ato das Disposições Constitucionais Transitórias, para instituir o piso salarial profissional nacional para os profissionais do magistério público da educação básica.

- Ministério da Educação.Conselho Nacional de Educação. Câmara de Educação Básica. Resolução no 3, de 8 de outubro de 1997. Fixa as diretrizes para os Novos Planos de Carreira e de Remuneração para o Magistério dos Estados, do Distrito Federal e dos Municípios.

. Ministério da Educação. Conselho Nacional de Educação. Câmara de Educação Básica. Resolução oㅡ 2, de 28 de maio de 2009. Fixa as diretrizes nacionais para os Planos de Carreira e Remuneração dos profissionais do magistério da Educação Básica Pública.

CATANZARO, M. \& ALGEBAILE, E. O trabalho docente em reconfiguração: tensões entre regulamentação e regulação na rede municipal de ensino do Rio de Janeiro. IX Seminário de La Red Estrado / Políticas Educativas para a América Latina: praxis docente y transformación social. Universidad de Chile, Santiago do Chile, Julio de 2012. 


\section{Trabalhonecessário}

Issn: 1808 - 799X

ano 11, no $17-2013$

COUTINHO, Carlos Nelson. Representação de interesses, formulação de políticas e hegemonia. In: TEIXEIRA, Fleury S. Reforma sanitária: em busca de uma teoria. São Paulo, Cortez, 1995. p.47-59.

CUNHA, Luiz Antônio. Educação, Estado e Democracia no Brasil. São Paulo/Brasília/Niterói, Cortez/ FLACSO/ EDUFF, 1997.

DUARTE, A. Políticas educacionais e o trabalho docente na atualidade: tendências e contradições. In: Políticas públicas e educação: regulação e conhecimento.Oliveira, Dalila Andrade e Duarte, Adriana (orgs). 1 ed. Belo Horizonte: Fino Traço Editora, 2011, vol. 1, p. 161-182.

DRAIBE, Sônia. As políticas sociais e o neoliberalismo. In: Revista USP, №17, março/ abril - 1993.

FOUCAULT, Michel. Nascimento da biopolítica. Curso dado no Collàge de France (1978-1979) / Michel Foucault; edição estabelecida por Michel Senellart; tradução Eduardo Brandão. - São Paulo: Martins Fontes, 2008. - (Coleção tópicos).

FONTES, Virgínia. Conversando sobre política e classes sociais na atualidade. In: Anais do $1^{\circ}$ Ciclo de Conferências: Políticas que produzem educação / Estela Scheinvar (et.alli). - Rio de Janeiro: Faculdade de Formação de Professores, 2008.

FRIGOTTO, G. Reformas educativas e o retrocesso democrático no Brasil nos anos 90. In: LINHARES, C. (org.). Os Professores e a Reinvenção da Escola: Brasil e Espanha. São Paulo : Cortez, 2001.

. Os delírios da razão - crise do capital e a metamorfose conceitual no campo educacional. In: Pedagogia da exclusão: o neoliberalismo e a crise da escola pública / Michel W. Apple...[et al.]; Pablo Gentili (org.), 13ª ed.- Petrópolis, RJ: Vozes, 2007. - (Coleção estudos culturais em educação).

GRAMSCI, Antonio. Cadernos do cárcere. Volume 3: Maquiavel. Notas sobre o Estado e a política. Rio de Janeiro: Civilização Brasileira, 2000.

. Cadernos do cárcere. Volume 5: II Risorgimento italiano. Para uma história das classes subalternas. Rio de Janeiro: Civilização Brasileira, 2002. GRUPPI, Luciano. O conceito de hegemonia em Gramsci. 4ª Ed. Rio de Janeiro: Graal, 2000.

LESSARD, Cloude. Autonomia Profissional. In: Dicionário de trabalho, profissão e condição docente / Organizadoras, Dalila Andrade Oliveira, Adriana Maria 


\title{
Trabalhonecessário
}

\author{
Issn: 1808 - 799X \\ ano 11, no $17-2013$
}

Cancela Duarte, Lívia Maria Fraga Vieira. - Belo Horizonte: UFMG/Faculdade de Educação, 2010. I CD-ROM.

MARTINS, Angela. Autonomia e Educação: a trajetória de um conceito. Cadernos de Pesquisa, n.115. Fundação Carlos Chagas, 2002.

OLIVEIRA, Dalila Andrade. Política Educacional e a re-estruturação do trabalho docente. In: Educação e sociedade. Campinas, 2007.

- O trabalho docente na América Latina - Identidade e profissionalização. Revista Semestral da Escola de Formação da CNTE (ESFORCE). - vol. 2 Números 2/3 - Brasília - janeiro a dezembro, 2008.

TORRES, Rosa Maria. Melhorar a qualidade da educação básica? As estratégias do Banco Mundial. In: O Banco Mundial e as Políticas Educacionais, Lívia De TOMMASI, Miriam Jorge Warde, Sérgio Haddad (orgs.). $-2^{\circ}$ ed. - São Paulo: Cortez, 1998.

Data de recebimento: $30 / 04 / 2013$

Data de aprovação 05/11/2013 